\title{
Chapter 5 \\ Conceptual and Empirical Approaches to Mapping and Quantifying Land-Use Intensity
}

\author{
Karlheinz Erb, Maria Niedertscheider, Jan Philipp Dietrich, Christoph \\ Schmitz, Peter H. Verburg, Martin Rudbeck Jepsen and Helmut Haberl
}

Keywords Global land-use - Land-use intensification - Colonization of ecosystems · Intensity indicators · GIS

\subsection{Introduction}

Land use is a pervasive driver of change in the earth system (Steffen et al. 2007; Turner et al. 2007). Today, the majority of the ice-free terrestrial surface has been affected in one way or another by human land use (McCloskey and Spalding 1989; Sanderson et al. 2002), and since the beginning of agriculture, more than one third

K. Erb $(\varangle) \cdot$ M. Niedertscheider $\cdot$ H. Haberl

Institute of Social Ecology Vienna (SEC), Alpen-Adria University,

Schottenfeldgasse 29, 1070 Vienna, Austria

e-mail:karlheinz.erb@aau.at

M. Niedertscheider

e-mail: maria.niedertscheider@aau.at

J. P. Dietrich

Sustainable Solutions (RD3), Potsdam Institute for Climate Impact

Research (PIK), Telegrafenberg A 51, 14473 Potsdam, Germany

e-mail: dietrich@pik-potsdam.de

C. Schmitz

Climate Impacts and Vulnerabilities (RD2), Potsdam Institute for Climate

Impact Resarch (PIK), Telegrafenberg A 31, 14473 Potsdam, Germany

e-mail:schmitz@pik-potsdam.de

P. H. Verburg

Institute for Environmental Studies (IVM), VU University Amsterdam,

De Boelelaan 1087, 1081 HV Amsterdam, The Netherlands

e-mail: peter.verburg@vu.nl

\section{R. Jepsen}

Department of Geosciences and Natural Resource Management, Section of Geography,

University of Copenhagen, Øster Voldgade 10, 1350 Copenhagen K, Denmark

e-mail: mrj@geo.ku.dk

H. Haberl

e-mail: helmut.haberl@aau.at 
of all pristine terrestrial ecosystems have been converted to human-controlled, permanently managed ecosystems with fundamentally altered ecological characteristics (Erb et al. 2007). By using the land, human societies alter structures and processes in ecosystems and thereby substantially affect global land cover, biodiversity, biogeochemical cycles of carbon, water, nitrogen, and many other patterns and processes, with far-reaching consequences for ecosystems and human well-being (Millennium Ecosystem Assessment 2005). Land use, on the one hand, provides the basis of nutrition, an array of resources and many essential ecosystem services to society. On the other hand, land use is increasingly jeopardising ecosystem functioning and thus threatens the biophysical basis of humanity. This fundamental trade-off related to land use leads to the emergence of an interdisciplinary research agenda, land-system science (Global Land Project 2005), which seeks to improve the observation of land changes as well as the understanding of these changes in a systemic context, including the interactions and feedback loops among social and natural systems (Turner et al. 2007).

Changes in land use encompass two different elements: changes in land cover, i.e., a shift from one land cover type to another such as the conversion of pristine forests to cropland, and changes in land-use intensity, also termed land-cover modification, i.e., a change in the intensity with which a certain land cover type is used (Lambin et al. 2001). Depending on the definition used, intensification denotes increases in inputs (e.g., energy, fertiliser or water) or increases in outputs per unit of land or changes in management practices (e.g., crop rotation, cropping intensity, or technology). Many negative environmental effects are associated with intensification processes, such as nutrient leaching, groundwater and air pollution, or soil degradation (IAASTD 2009; Matson et al. 1997), but environmental benefits exist as well, such as the possible benefits of reduced land demand, which sets land free for biodiversity conservation or carbon sequestration (see, e.g., Burney et al. 2010; Green et al. 2005). Empirical evidence suggests that yield increases in agriculture resulting from intensification were a major factor in the increase in global food production, in particular after World War II, helping to reduce the rate of land expansion in recent decades (FAOSTAT 2011), and this trend is forecast to prevail also over the next decades (Alexandratos 2006; Bruinsma 2003).

Changes in land-use intensity are crucial, but although their importance is widely acknowledged on a general level, they have in our view not received the attention that they deserve in mainstream land-change research over the last decades. The majority of current land-change studies focus on changes in land cover and the effects of such changes on processes such as climate change (Lambin et al. 2000, 2001). Huge progress in land-cover change research was enabled by the increasing availability of remote sensing-derived land-cover data. The soaring amount, resolution and quality of land-cover data have helped to gauge the importance of land-use change as a pervasive driver of global environmental change. This was decisive for establishing land-use change as an important research topic in environmental and sustainability science. Nevertheless, this focus on land-cover change distracted attention from landuse intensification and extensification processes because most changes associated with intensification are not related to changes in land cover and are thus not detectable 
by remote sensing (Erb 2012; Erb et al. 2007; Verburg et al. 2011). To illustrate this by extremes: changes in the land system, e.g., from shifting cultivation to permanent agriculture, also change land cover. In contrast, the intensification of permanent agriculture may result in changes that are not detectable by remote sensing or that cause only minor (and thus negligible) land cover changes, if any, regardless of whether intensification refers to increased rates of inputs or increasing production.

Interestingly, this lack of attention is a modern phenomenon. In the mid-1960s, a strong interest in agricultural change and intensity emerged, in particular in the social sciences. The publication of Ester Boserup's book on the conditions of agricultural growth (Boserup 1965) and the rediscovery of the work of A. Chayanov (Chayanov 1986) represent milestones with this regard (Turner and Shajaat Ali 1996). In particular, Boserup's open polemic against Malthusian concepts of population growth and its relation with food production inspired many scholars to hypothesise and empirically analyse the interrelation of population pressure, technological change and land-use intensification (see, e.g., Allen 2001; Blaikie and Brookfield 1987; Grigg 1979; Pingali et al. 1987; Shriar 2000; Tiffen et al. 1994). However, much of this literature was based on a rather implicit understanding of land-use intensity that was not aimed at empirical testing of hypotheses or the development of rigorous metrics (see Lambin et al. 2000; Netting 1993; Shriar 2000). Only a few attempts at defining measurable indicators or metrics of land-use intensity have been made to date (see, e.g., Herzog et al. 2006; Keys and McConnell 2005; Ruthenberg 1980; Shriar 2000; Turner and Doolittle 1978).

The development of conceptually sound and empirically feasible metrics of landuse intensity is thus a precondition for advancing our understanding of past, on-going and future land-change processes, including the complex feedback loops among production and consumption systems (Erb 2012; Lambin and Meyfroidt 2011). Boserup's work on land-use intensity offers a conceptual framework that can serve as source of inspiration for land system science and is well suited to providing a starting ground for returning this aspect of land-use change to the agenda of land-change science.

In this chapter, we reflect on Boserup's notion of land-use intensification processes, review how her work on land-use intensification was used and further developed, and derive insights on conceptually sound measures of land-use intensity. Starting from this basis, we explore three promising approaches that have been suggested as measures of land-use intensity by providing a measure of reference against which output intensity (e.g., yield) can be measured. These three approaches are (a) the technical efficiency (TE) approach (Licker et al. 2010; Neumann et al. 2010; Verburg et al. 2000), (b) the $\tau$-factor measure of agricultural land-use intensity (Dietrich 2011; Dietrich et al. 2012) and (c) the indicator framework "human appropriation of net primary production" (HANPP) (Erb et al. 2009b; Haberl et al. 2007; Vitousek et al. 1986). Based on conceptual and empirical comparisons of these three approaches, we conclude by discussing future opportunities and challenges related to land-use intensity research. 


\subsection{Boserup's Notion of Land-Use Intensification}

In her book The Conditions of Agricultural Growth: The Economics of Agrarian Change under Population Pressure (1965), Boserup outlines her notion of the interplay of population growth, land-use change and agricultural development. In this book, she develops a "historical model" (Brookfield 2001), scrutinising the relation between population growth and agricultural development related to the transition from shifting cultivation to permanent agriculture. Boserup describes the intensification of agriculture as the acceleration of the frequency of harvest events in (shifting) agriculture. She claims that for any given area, human societies move through a universal series of stages of increasing land-use intensity, driven by population growth. As long as population densities are low, only a limited fraction of the total area is cropped; after 1 or 2 years, the land is left idle to recover during several year-long periods of natural fallow. With increasing population density, the fraction of the area under crops increases, and the length of the fallow period is reduced, until the ecosystem changes from a forest mosaic to a shrub mosaic because the fallow time is not sufficient for the trees to grow back fully. In the next stage, shrubs are replaced by grasses. In the final stage, fallow disappears completely or is even replaced by multi-cropping. This increase of cropping intensity is associated with an increase in overall production per unit area and per year. In her original outline, Boserup discerns five archetypes of farming systems along an axis of cropping intensity, from slash and burn agriculture (forest fallow) through bush-fallow to permanent agriculture with multi-cropping (no fallow, more than one harvest per vegetation cycle or year). According to her description, increasing food demand resulting from population growth is the trigger for this development and provides the means to achieve higher yields through an increased workforce.

Although it is only a short book of approximately 100 pages and contains (almost) no figures, tables or graphs but has compelling persuasive power, Boserup's work triggered an avalanche of scientific reviews, critiques, affirmations, contentions, and pronouncements (e.g., Allen 2001; Grigg 1979; Hunt 2000; Robinson and Schutjer 1984; Shriar 2000; Turner and Shajaat Ali 1996). Boserup's basic assertion that agricultural change is a response to uncontainable population pressure forcing agrarian population to pay the price of decreasing labour productivity to achieve higher yields through changed technology was soon to become mainstream in the understanding of agricultural development (Turner and Fischer-Kowalski 2010; Chap. 1 of this publication). Her approach, driven by a fundamental opposition to the Malthusian notion of a "population trap", became a key concept relating agricultural expansion and population growth (Brookfield 2001; Lambin et al. 2000; Turner and Doolittle 1978; Turner et al. 1977). In particular, interdisciplinary research fields-cultural ecology, ecological anthropology, political ecology, and ecological economics, to name but a few-readily adopted Boserup's theories. Since then, many empirical studies have investigated the generalisability of this theory, but they have also formulated nuances and exceptions that allowed for a more robust understanding of land-use change processes (Lambin et al. 2001; Turner and Shajaat Ali 1996). 
Boserup's motivation was to challenge the Malthusian belief that the slow, linear growth in yields acts as a "food ceiling" for the faster, exponential growth in population, leading to a "Malthusian trap" of stagnation or even a reduction of the standard of living. She and her followers largely succeeded in reversing this point of view, which had been prevalent at her time in most public discourse, arguing that increases in population act as drivers for adopting technologies and management strategies that increase production proportionally to population growth. According to this new paradigm, it is not the state of technology that determines the level of cropping intensity; instead, technology is envisaged as being endogenously driven by the increasing population pressures-hence, population density is determining land-use intensity. Boserup builds her perspective on the observation that many of the endogenous technological strategies are known to the community long before adoption but remain unemployed due to disadvantages in their application. According to her hypothesis, which was supported by evidence in later studies (Chayanov 1986, see Turner and Shajaat Ali 1996) but also vehemently opposed (see Hunt 2000), along with the technological changes and increased production comes a decline in labour productivity, i.e., the amount of output per working hour. Over the long run, this process transforms both the physical and social structures, which is the theme of her subsequent book Population and Technological Change: A Study of Long-Term Trends (Boserup 1981).

Boserup's model is reductionist, as it is based on only two primary forces driving change: population growth and the need to combat the loss of production through the natural deterioration of the soil. In particular, it largely neglects factors that are related to the industrial mode of subsistence, such as market forces, as well as the tremendous increases in labour productivity that are enabled by fossil fuel based technology, an area-independent energy carrier that removed many of the constraints of agrarian society (Erb et al. 2008; Fischer-Kowalski and Haberl 2007; McNeill 2001; Sieferle et al. 2006). ${ }^{1}$ In this matter, Grigg (1979) also refers to land expansion as a factor that disproves Boserup's notion of agricultural intensification. However, land expansion without agricultural intensification is restricted to regional biophysical and geographical conditions. Thus, after a certain level of cropland extent is reached, Boserup's theory again holds true, and rising population density will be met by agricultural intensification. Boserup's basic argument, however, that the level of technology is not a determining factor of population density, remains valid, and her oeuvre can be considered a vivid illustration of the argument that there is no "natural carrying capacity" for societies in a particular region (Cohen 1995; VanWey et al. 2005).

\footnotetext{
${ }^{1}$ Boserup devotes Chap. 13 in the "Conditions of agricultural growth" (Boserup 1965) to this topic and concludes that transferring technology to societies without a fully industrialized urban sector will most likely not realize the full potential of technology due to the lack of skills among the farm workers (p. 120).
} 


\subsection{Measuring Land-Use Intensity}

Metrics of land-use intensity usually describe either the input or the output side of land management. Different schools of thought value these two perspectives differently. Some writers emphasise the input side, as the intensification of agriculture usually involves an increase in the frequency of cultivation, in inputs, in skills or in other technological means. Boserup, by focussing on the frequency of cropping, shares this view. Her notion of cropping frequency as the best metric for land-use intensity is inspired by the observation that, under pre-industrial conditions, the annual crop yields of a parcel of land can be modified only slightly and that only an increased frequency of cropping (or, a higher share of land under direct cultivation; Boserup 1981, see Shriar 2000) allows an increase in production. Her assumption on the output-side remains implicit, however. She assumes only that production is increasing but does not elaborate on this aspect of intensification. Other authors even openly assert that the level of production is not relevant for the measurement of intensity. In such a view, only the input variables such as the workers' labour time, energy, capital, technique-skills, or the frequency of cultivation are relevant (Brookfield and Hart 1971, see Turner and Doolittle 1978).

This view is contested by many scholars, who propose output metrics for studying land-use intensification. In biophysical terms, output intensification relates to increases in production per unit area and period of time, e.g., tons of cereals per hectare and year, i.e., agricultural yield (Lambin et al. 2000). In these terms, output intensification has a reciprocal relation with area expansion. By definition, the amount of land required to produce a predefined amount of output is inversely correlated to yield (Burney et al. 2010; Netting 1993; Rudel 2009). Netting (1993) asserts that observing outputs has the advantage of making no presumption regarding the effect of inputs on productivity, a view shared by Shirar (2000), whereas Turner and Doolittle (1978) argue that output-indicators provide the better-suited metric because the ultimate purpose of many agricultural studies is to explain why yields have increased per unit land area and time, an argument also proposed by Hunt (2000).

Measuring outputs, however, is not straightforward (Hunt 2000; Shriar 2000). In addition to questions of data availability and robustness, there are also challenges related to the unit of measurement (e.g., dry matter, fresh weight, energy, nutritive value, or monetary value) and the methodology used to consistently measure output. Because many land-use systems periodically leave agricultural fields idle to maintain soil fertility (fallow), it is important to relate the output flow to the full production cycle to generate consistent values. Such data, however, are usually not readily available, although recent data compilations provide some new insights (FAOSTAT 2011; Shriar 2000; Siebert et al. 2010). Yields (usually measured as the fresh weight of commercial products) and their equivalents in terms of dry matter, energy or carbon content or nutritive value are highly species-specific, which does not facilitate producing a single metric of land-use intensity. Furthermore, substantial variations in agricultural and forestry yields result from differences in climate and soil conditions. In principle, the actual yield may be relatively high with relatively low input 
intensity in areas where local conditions are favourable for crop growth. In areas with unfavourable conditions for crop growth, the yield may be relatively low, despite relatively efficient land management practices. Measuring land-use intensity, however, requires the exclusion of influences caused by the physical environment, such as differences in soil or climate conditions. Therefore, yield data alone cannot serve as indicators of output intensity.

Measuring output intensification thus requires the establishment of an unambiguous and meaningful measure of reference (see, e.g., Hunt 2000). In the literature, three output-based concepts are available that allow to create global, spatially explicit information regarding land-use intensity. These concepts differ in their conceptualisation, the construction of a measure of reference, and their precise meaning as well as their field of application: (a) the technological efficiency (TE) approach (Licker et al. 2010; Neumann et al. 2010; Verburg et al. 2000), an approach that compares actually achieved yields of cropland cultivars with the maximum yield level achieved at locations subject to similar bioclimatic conditions; (b) The $\tau$-factor (tau-factor) measure of agricultural land-use intensity (Dietrich 2011, Dietrich et al. 2012), which applies a dynamic vegetation model for constructing a reference yield value by standardising management effects on cropland and comparing this value with actual yields; and (c) the human-appropriation-of-net-primary-production (HANPP) (Erb et al. 2009b; Haberl et al. 2001, 2004, 2007), an indicator that assesses the effect of land conversion and biomass harvest on ecological energy flows, using the potential NPP (prevailing hypothetically in the absence of land use) as a measure of reference.

\subsubsection{The Technical Efficiency Approach}

Metrics for the efficiency of agricultural production are used in various studies as indicators of the intensity of land use (Neumann et al. 2010; Tian and Wan 2000; Verburg et al. 2000). This approach originates from economics, where metrics of TE (i.e., the effectiveness with which a given set of inputs is used to produce a certain quantity of outputs) were developed for calculating the efficiencies of firms or other economic units (Coelli 2005). Because agricultural farms are a special form of economic unit, this econometric methodology can also be used to calculate farm efficiencies, and in particular, the efficiency of agricultural production. In spatial analysis across larger scales, the agricultural production within one spatial unit (e.g., a 5 arc min resolution pixel) is considered as one uniform economic unit. The TE metric is then calculated by comparing actual yields with the yields derived from a stochastic frontier production function, which represent the maximum yield given environmental conditions and available technologies (Neumann et al. 2010). Deviations from the frontier function can be caused either by inefficiency of production or by statistical noise (e.g., due to data inaccuracies). Figure 5.1 displays a schematic illustration of the TE concept. Inefficiency of production is interpreted as a measure of the intensity of land management, assuming that the maximum yields obtained under given environmental conditions represent the most intensive (in economics labelled "optimal") management. 


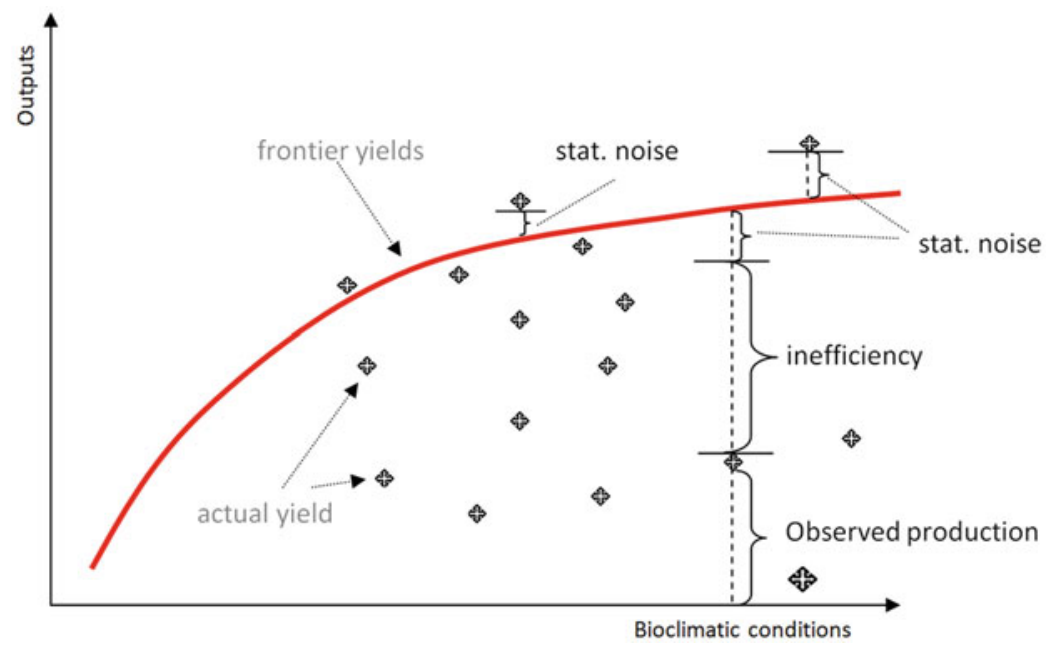

Fig. 5.1 Schematic representation of the TE approach. The stochastic production frontier (after Coelli 2005; red solid line) is based on the highest observed outputs under the inputs accounting for random noise. Efficiency is defined as the ratio of actual yields to frontier yields. The frontier production can lie above or below the frontier production function, depending on the noise effect (data uncertainty)

Neumann et al. (2010) calculated frontier yields and efficiencies of wheat, maize and rice at a global scale, using the following formula and data:

$$
\begin{gathered}
\ln \left(q_{i}\right)=\beta_{0}+\beta_{1} \ln \left(\text { temp }_{i}\right)+\beta_{2} \ln \left(\text { precip }_{i}\right)+\beta_{3} \ln \left(\text { par }_{i}\right) \\
+\beta_{4} \ln \left(\text { soil_constr }_{i}\right)+v_{i}-u_{i}
\end{gathered}
$$

where $q_{\mathrm{i}}$ is the actual grain yield (from Monfreda et al. 2008), temp $p_{\mathrm{i}}$ is the deviation from the optimal monthly mean temperature, precip $_{\mathrm{i}}$ is the precipitation, $p a r_{\mathrm{i}}$ is the photosynthetically active radiation, soil_constr $r_{\mathrm{i}}$ are soil fertility constraints (all of these bioclimatic variables are taken from available global datasets) (see Neumann et al. 2010), $v_{\mathrm{i}}$ is a random error (accounting for the statistical noise) and $u_{\mathrm{i}}$ accounts for the inefficiency effects of production. In the study of Neumann et al. (2010), this latter term is described as a function of irrigation, slope, agricultural population (used as a proxy for labour availability), market accessibility and market influence from various spatially explicit data sources (see Neumann et al. 2010). Licker et al. (2010) used a similar method based on comparing actual yields with the highest obtained yield to calculate the yield gap in different climate zones based on information on the growing degree days and a crop soil moisture index; they achieved similar results to those of Neumann et al. (2010). In a study in China, Verburg et al. (2000) used the TE approach to also study the inefficiency in land use by comparing the actual cropping index (number of crops per year) with the frontier cropping index under the local climatic conditions. 
Using efficiency, measured as the ratio between actual yields to maximum achieved yields under comparable conditions, as a proxy for the intensity of land management allows the consideration of variations in biophysical conditions as determinants of the potential yields. The frontier yield represents the currently highest yield under the local environmental conditions. If the best available technology changes, the frontier yield will change as well, i.e., it will generally increase. This increase automatically affects the distance to the frontier yield of non-adopting farms. Thus, the reference value subsumes the current technology level—this is important to note when interpreting the TE as a proxy for agricultural intensity and is one of the reasons that there has been some criticism on the suitability of the indicator for that purpose (Dietrich et al. 2012). The difference between the frontier yield and the actual yield has been interpreted as the "yield gap" at a location, assuming that more efficient management could change the actual yield to the frontier yield.

\subsubsection{The $\tau$-Factor}

Another yield-based approach is the $\tau$-factor (Dietrich 2011; Dietrich et al. 2012). Although it requires similar inputs to those of the TE approach, it was developed as a direct measure of agricultural land-use intensity. The $\tau$-factor is based on the idea that yield can be considered an indicator of agricultural land-use intensity that is affected by variations in environmental conditions. When two locations with identical environmental conditions growing the same crop are compared, any difference in yield can be attributed to the differences in agricultural land-use intensity in these two locations. If environmental conditions differ, however, the differences in land-use intensity are superimposed by variations in environmental conditions. The $\tau$-factor approach tackles this problem by comparing observed agricultural yields with a reference yield that would be achieved at each site with the same level of input intensity. This reference yield is constructed to ensure that only the differences in environmental conditions are reflected by setting land-use intensity to a constant level. The $\tau$-factor can then be defined as the ratio of actual yield to reference yield. Variability of the $\tau$-factor can thus legitimately be assumed to be solely caused by differences in agricultural land-use intensity, whereas the variations in the reference value can be assumed to be purely environmentally determined.

Dietrich et al. (2012) calculate and map the $\tau$-factor at the global scale by using the "Lund-Potsdam-Jena dynamic global vegetation model with managed land" (LPJmL) (Bondeau et al. 2007). Actual yields are based on the national yield data of the Food and Agriculture Organization of the United Nations (FAO) (FAOSTAT 2011), downscaled by the LPJmL. Reference yields are computed by simulating spatial patterns of crop yields under constant management practices (all managementdependent parameters in the model are set to a constant level). The results of this analysis are shown in Fig. 5.2. The FAO data used by Dietrich et al. (2012) contains only information on harvest yields (yield per area for each harvest event) but not the yields per unit area under land use (land-use yields), which causes changes in cropping 


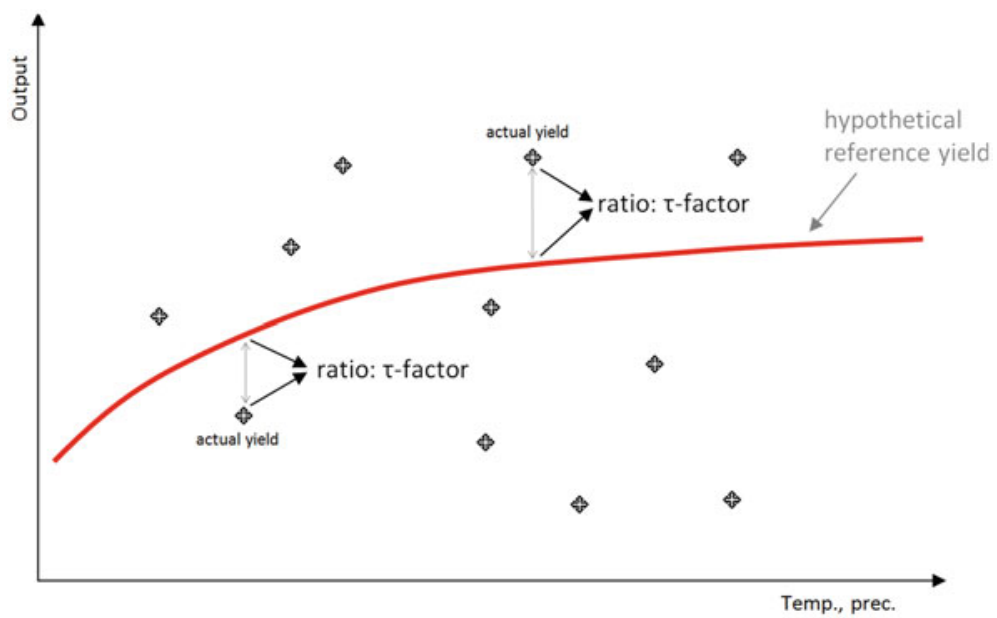

Fig. 5.2 Schematic representation of the $\tau$-factor approach. The hypothetical yield (solid red line) is constructed by setting all management-dependent parameters in the global dynamic vegetation model to a constant level. The $\tau$-factor is the ratio of the actually achieved yield to the reference yield

intensity (the intensity indicator suggested by Boserup) to be undetectable. This is a limitation of this specific calculation rather than a characteristic of the general methodology and can be overcome by using data regarding land-use yields instead of harvest yields. Such data, however, are not readily available at the global level for individual crops (Portmann et al. 2010). Likewise, in its current implementation, the $\tau$-factor is calculated for cropland, but it could be conceptually extended to any land-use class for which a yield can be determined, such as grazing or forestry. For land-use classes such as infrastructure, the $\tau$-factor cannot be derived.

The $\tau$-factor has been used to implement technological change in an economic land-use model (Dietrich 2011). This improved model was applied in several studies related to questions of future agricultural land use (Popp et al. 2011; Schmitz et al. 2012).

\subsubsection{Human Appropriation of Net Primary Production}

The "human appropriation of net primary production" (HANPP) is an integrated socio-ecological accounting framework that uses a reference value determined only by natural conditions: the productivity of the potential natural vegetation, i.e., the vegetation assumed to exist in the absence of land use. In the HANPP framework, "productivity" is operationalised as net primary production, i.e., the carbon accumulated by green plants through photosynthesis, less the metabolic needs of the plant. HANPP measures changes in trophic energy flows in ecosystems resulting 
from all types of land use (infrastructure, cropland, grazing, and forestry) and can as such be regarded as an aggregate indicator of land-use intensity (Erb 2012; Erb et al. 2009b; Haberl et al. 2001, 2007). HANPP encompasses all land-use classes, including cropping (annual and permanent), grazing, forestry and infrastructure, in contrast to the two above-discussed concepts, which only refer to agriculture in their current implementations.

HANPP is defined as the sum of (a) the changes in productivity resulting from land conversion $\left(\triangle \mathrm{NPP}_{\mathrm{LC}}\right)$ and $(\mathrm{b})$ the biomass harvested or destroyed during harvest $\left(\mathrm{NPP}_{\mathrm{h}}\right.$; see, e.g., Erb et al. 2009b; Haberl et al. 2007). $\Delta \mathrm{NPP}_{\mathrm{LC}}$ may result from the replacement of natural vegetation with artificial ecosystems such as settlements, industrial areas, infrastructure or other impervious surfaces. In agro-ecosystems, NPP is also directly influenced by management activities such as irrigation and fertilisation. Hence, the NPP of agro-ecosystems often differs from the NPP of the natural ecosystems they replace. By extracting biomass from ecosystems for socioeconomic purposes, humans alter the amount of NPP remaining in ecosystems. The total amount of biomass harvested or destroyed (e.g., through human-induced fires) is denoted as $\mathrm{NPP}_{h}$. $\mathrm{NPP}_{h}$ is calculated on the basis of a combination of national yield data with factors that allow for the accounting by-products, destroyed biomass fractions and pre-harvest NPP losses (for details see Haberl et al. 2007; Krausmann et al. 2008), and $\mathrm{NPP}_{\mathrm{h}}$ is downscaled to the grid level based on a probability index derived from the $\mathrm{NPP}_{0}$ pattern of the LPJ-DGVM (Bondeau et al. 2007; Gerten et al. 2004; Sitch et al. 2003) Only the biomass remaining in the ecosystem after harvest $\left(\mathrm{NPP}_{\mathrm{t}}\right)$ is available for carbon sequestration or as a food energy source for wild-living heterotrophic organisms. HANPP and its components are measured in the same units as NPP, that is, as flows of dry-matter biomass, carbon or energy.

HANPP accounts can provide spatially explicit information in an overall representation of one central aspect of land-use intensity, i.e., changes in trophic energy flows in ecosystems resulting from land use. The definition presented above (Fig. 5.3) allows for consistent long-term assessments using HANPP (Krausmann et al. 2012) and for spatially explicit HANPP assessments, e.g., Haberl et al. (2001, 2007). Land use sometimes reduces NPP or even prevents it altogether (e.g., soil sealing), but technologies such as irrigation, fertilisation or the use of improved crop varieties may also raise NPP above its natural potential. Such effects are significant and historically variable and should therefore be included in any comprehensive HANPP assessment.

However, HANPP has some weaknesses in determining land-use intensification due to technological improvements on cropland because technological improvements typically result in parallel increases in plant growth (NPPact) and harvest growth (NPPh). In consequence, the HANPP value remains unaltered (Krausmann et al. 2012). Conceptually, separately monitoring the two primary components of HANPP (NPPh and $\triangle$ NPPLC) allows the effects of improved technologies to be discerned because the increases of productivity then become visible as increasing NPPh and declining $\triangle$ NPPLC. In the current implementation, in which NPPh denotes the entire biomass harvested or killed during harvest (Erb et al. 2009b; Haberl et al. 2007), any yield increased due to NPPact neutral shifts in the harvest index (the fraction of the main product, e.g., grain, to the total plant, including straw; see 


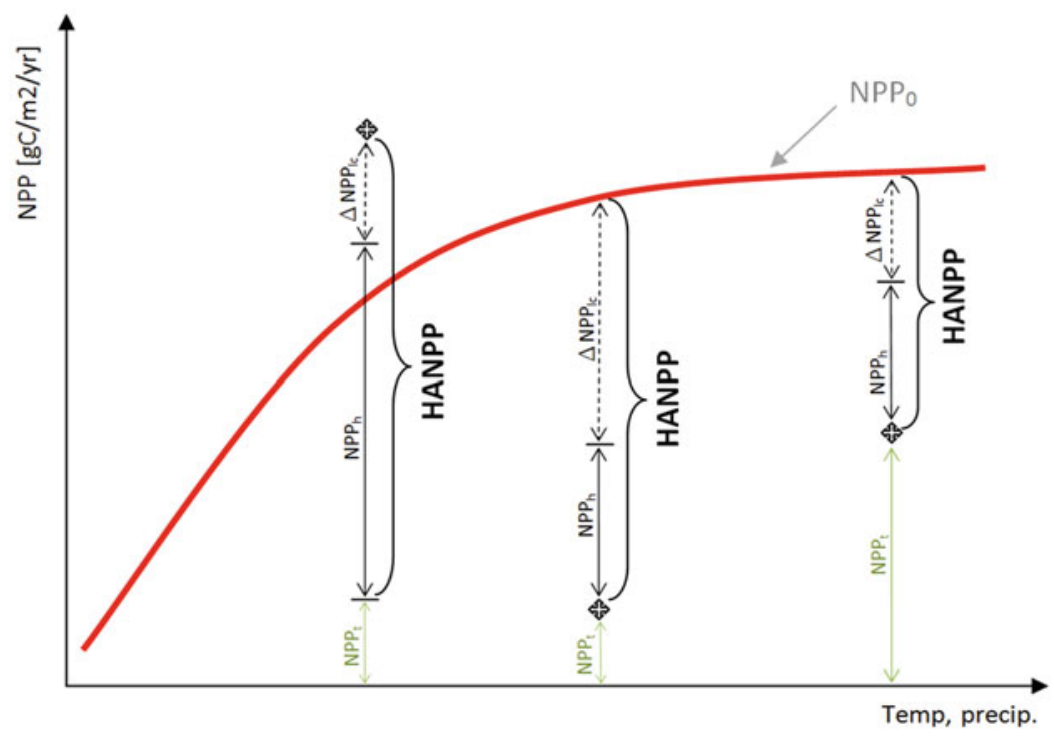

Fig. 5.3 Schematic representation of the HANPP approach. The HANPP can be defined as (1) the sum of productivity changes induced by land use $(\triangle \mathrm{NPPLC})$ and biomass harvest $(\mathrm{NPPh})$ and (2) the difference between the NPP of potential natural vegetation (NPP0) and the fraction of current NPP (NPPact) that remains in the ecosystem after harvest (NPPt). Please note that current NPP (the sum of NPPt and NPPh) can exceed NPP0 due to management (left example). For details, see text

Krausmann 2001) cannot be identified. However, as the HANPP frameworks assesses all biomass components separately (Krausmann et al. 2008), such effects would potentially become visible with modified aggregation schemes.

The basis of HANPP calculations is the quantification of the potential ecological energy flow $\left(\mathrm{NPP}_{0}\right)$. In contrast to the NPP of the currently prevailing vegetation $\left(\mathrm{NPP}_{\mathrm{act}}\right)$, which can be quantified using many different methods (Lieth and Whittaker 1975; Roy et al. 2001), $\mathrm{NPP}_{0}$ cannot simply be "measured", as it is a hypothetical point of reference in most regions of the globe. However, numerous models, including so-called Dynamic Global Vegetation Models (DGVMs), are available to calculate $\mathrm{NPP}_{0}$ on a global level (Cramer et al. 1999; Roy et al. 2001) and on regional levels. These models provide spatially explicit information regarding many ecosystem parameters and are built upon basic ecological information from sitespecific research (for a compilation of NPP data for forest ecosystems, see, e.g., Cannell 1982) that allows the reconstruction of $\mathrm{NPP}_{0}$. Simpler approaches are available based on empirical algorithms of the interrelation among NPP, mean annual temperature and precipitation (e.g., Lieth's "Miami model"; Lieth 1973; Zaks et al. 2007; see Fig. 5.3). These approaches build upon the finding that the most decisive factors influencing NPP in the absence of human activities are climate (above all, temperature and precipitation) and soil quality. Species composition, for example, plays a much smaller role. 


\subsubsection{Global Patterns of Land-Use Intensity Derived Using the Three Approaches}

Figure 5.4 shows maps of land-use intensity derived using the three above-presented approaches. The maps were drawn based on existing datasets, which were Neumann et al. (2010) in the case of TE, Dietrich et al. (2012) in the case of the $\tau$-factor and Haberl et al. (2007) in the case of HANPP. The TE map (a) displays the efficiency of the most dominant crop type (wheat, rice and maize) in each grid cell. The aggregated $\tau$-factor (b) was calculated as the mean $\tau$-factor for all crops occurring in one grid cell. The HANPP map displays the aggregated values of all land-use classes occurring in a grid cell.

\subsection{Comparison of the Three Approaches}

\subsubsection{Conceptual Differences}

In this section, we discuss the convergences and discrepancies between the TE approach, the $\tau$-factor and HANPP expressed as per cent of $\mathrm{NPP}_{0}$. Each indicator tells its own story of land-use intensity - the objective of this comparison is to illuminate the issue of the intricacies of measuring land-use intensity.

Table 5.1 and Figs. 5.1, 5.2 and 5.3 give an overview of the conceptual features of the three approaches. All of the indicators are applicable on regional as well as global scales in a spatially explicit manner. However, they show considerable variations in scope: whereas the TE, in its current implementation by Neumann et al. (2010), focuses on the cultivation of selected cereals (maize, wheat and rice), the $\tau$-factor, as implemented by Dietrich et al. (2012), considers a huge variety of cropland products (grouped into 11 crop groups). HANPP encompasses the entire land-use system and is calculated for cropland, grazing land, forest land, and settlement areas (Erb et al. 2009b; Haberl et al. 2007; Vitousek et al. 1986).

The three frameworks differ considerably in how the reference line is constructed, which results in substantial differences in the aspects of the land-use system that are considered. This is important to note when interpreting the results. The TE approach is based on the "frontier yields" (Fig. 5.1), defined as the highest currently achieved yield under the growing conditions of the location studied. Land-use intensity is measured as the ratio of actual yields to frontier yields, i.e., as the deviation of actual yields from the highest currently technologically achievable yields. Low TE (near zero) indicates that the land in a certain region is managed inefficiently; in this case, one may assume that there is a high potential for further yield increases. The $\tau$-factor and HANPP relate observed yield data and data on biomass appropriation to simulated reference lines, calculated by dynamic global vegetation models (Bondeau et al. 2007). The $\tau$-factor refers to modelled hypothetical yields of the same crop (reference yields: under constant land management), whereas HANPP uses natural 


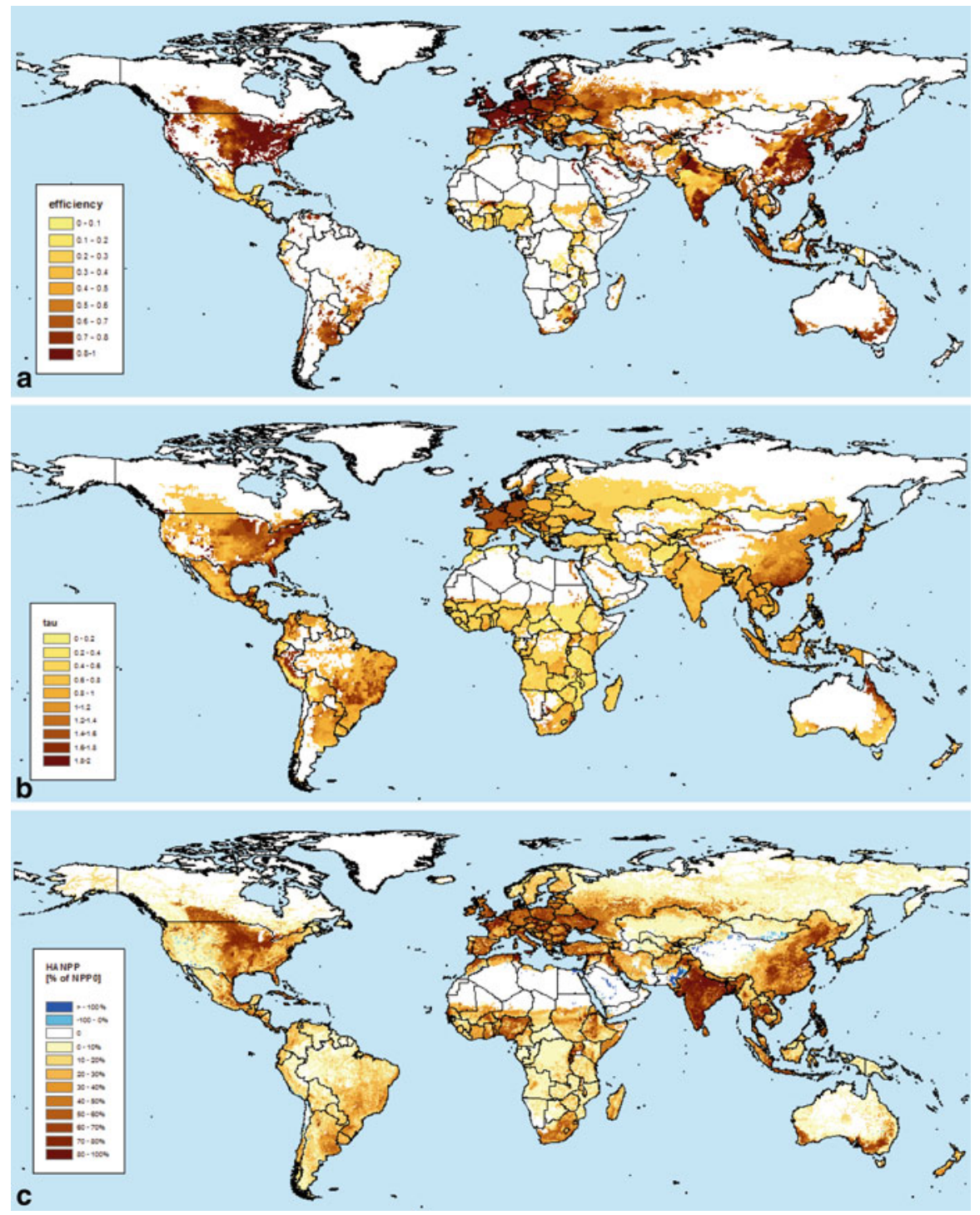

Fig. 5.4 Aggregated land-use intensity maps based on a global TE, $\mathbf{b}$ the $\tau$-factor, and $\mathbf{c}$ HANPP. For details see text. (Sources: Based on the following datasets: a: Neumann et al. 2010, b: Dietrich et al. 2012, c: Haberl et al. 2007 (HANPP))

ecosystem conditions $\left(\mathrm{NPP}_{0}\right)$ as a reference. The $\tau$-factor, calculated as the ratio between actual yields and reference yields, can range from zero to greater than one. For example, a factor of two would indicate that current yields are twice as high as the reference yields. $\mathrm{NPP}_{0}$, the reference for HANPP assessments, denotes the productivity of natural ecosystems (i.e., the ecosystems that would prevail without 


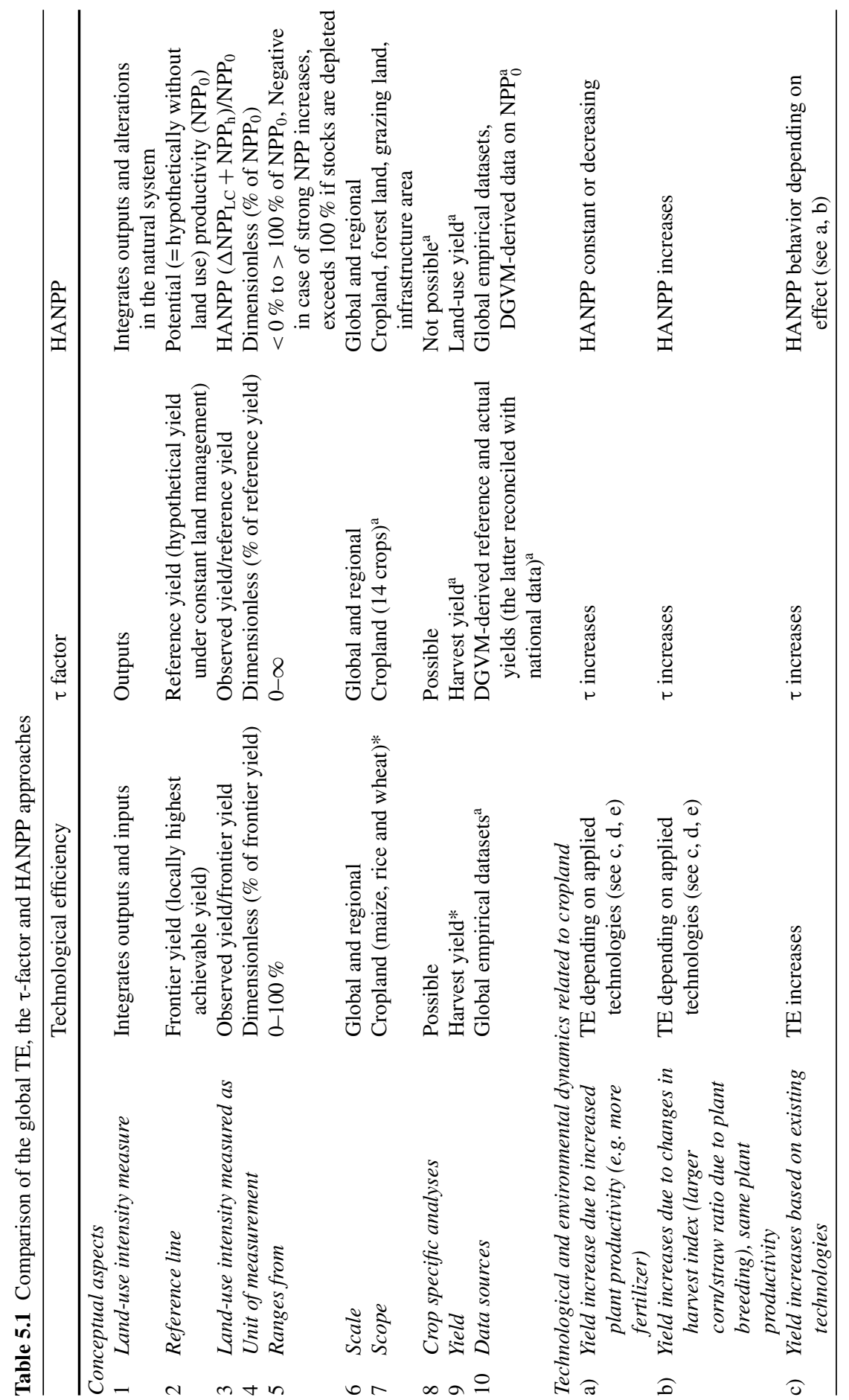




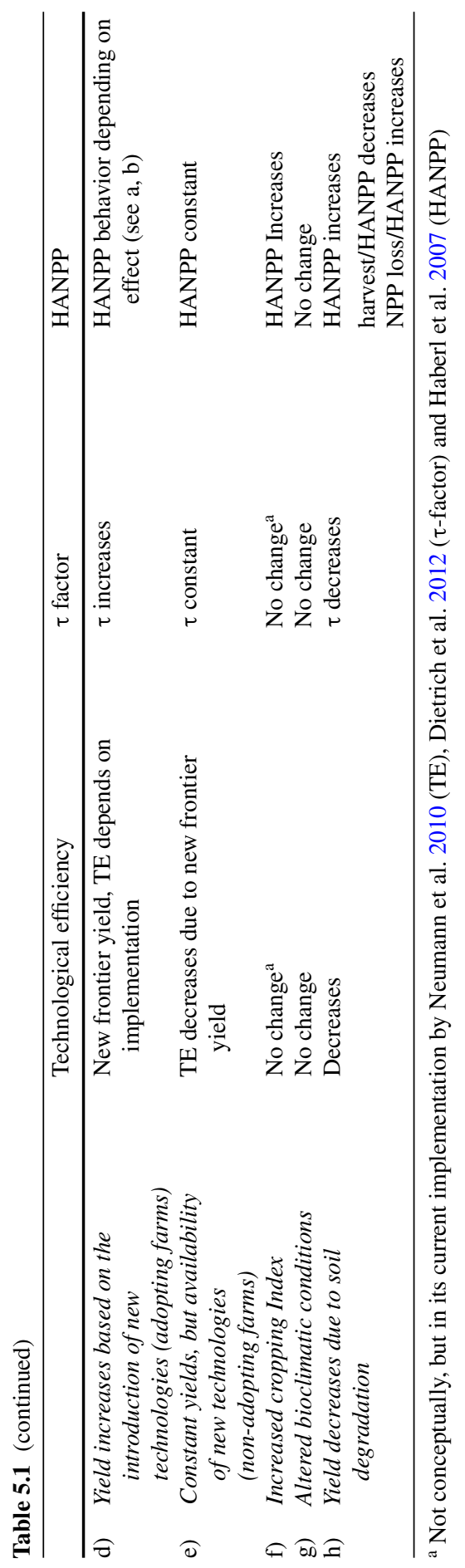


human land use), and HANPP can range from negative values below $-200 \%$ of $\mathrm{NPP}_{0}$, in cases where actual productivity surpasses $\mathrm{NPP}_{0}$, up to $100 \%$ of $\mathrm{NPP}_{0}$ in regions with very intensive cropland agriculture. When biomass stocks (i.e., accumulated NPP) are exploited to an extent that exceeds the accumulation time (stock depletion, e.g., deforestation), HANPP can exceed $100 \%$ (Erb et al. 2009b).

The $\tau$-factor uses output (yield) alone as a measure of land-use intensity. HANPP accounts combine information on outputs (harvest) with alterations of the natural state, i.e., of the natural productivity of each site, and TE combines information regarding outputs with inputs, analysing factors that influence the inefficient use of production factors. All indicators are dimensionless, with TE ranging between 0 and $100 \%$ and $\tau$ having any value $>0$. HANPP, in contrast, can become negative or exceed $100 \%$ (see above); however, in most cases, HANPP ranges between 0 and $100 \%$.

Table 5.1 also lists the response of the three indicator frameworks to altered technological and environmental dynamics related to the cropland system. All three indicators remove the effect of climatic and soil conditions on yield and thus render differences in land management visible. Increases of cropland yields due to increased plant productivity, e.g., through increased use of fertilisers, pesticides, or irrigation, are depicted by both TE and $\tau$. HANPP, in contrast, does not depict this important aspect of land-use intensification. If the increases in yield stem from increases in NPP compared with the previous state, two counteracting effects can be observed: $\triangle \mathrm{NPP}_{\mathrm{LC}}$ decreases, and $\mathrm{NPP}_{\mathrm{h}}$ increases. If the increase in $\mathrm{NPP}_{\text {act }}$ is greater than the increase in harvest $\left(\mathrm{NPP}_{\mathrm{h}}\right)$, HANPP may even decline as $\mathrm{NPP}_{\mathrm{h}}$ grows.

In contrast, among the compared implementations of the different approaches, HANPP has two advantages: (1) it is an indicator of overall land-use intensity that encompasses all land-use classes and is not restricted to cropland or single crops, and (2) on cropland, HANPP is able to detect changes in cropping intensity, that is, in the number of harvests per year. Cropping intensity may be lower than one (fallow) or higher than one (multi-cropping). This aspect of land-use intensity was central to Boserup's definition of land-use intensity. Declining fallow land over time results in increasing HANPP values. The TE and the $\tau$-factor, in their current implementation, however, explicitly focus on harvest yields (i.e., the yields per harvest event); they do not consider the fraction of land lying fallow. However, this difference among HANPP, TE and the $\tau$-factor is only a matter of the current implementation and not a conceptual shortcoming. TE and the $\tau$-factor could also be calculated based on land-use yields (i.e., yields per unit of cropland area including fallow), which would allow the proportion of fallow land to be included in the measurement of land-use intensity. This inclusion would not be straightforward and simple, due to data limitations and conceptual intricacies. TE and the $\tau$-factor are defined for single crops, whereas fallow land is an integral part of crop rotation systems; hence, its integration would require assigning fallow areas consistently to single crops.

The use of advanced crop varieties to increase production, for example, by increasing harvest indices (the ratio of commercial harvest, e.g., grain, to the total crop plant biomass at the time of harvest) can be depicted with the $\tau$-factor as well as with the HANPP concept, even in cases when the overall plant productivity (NPP) 
is not altered. In the case of TE, such changes result in complex outcomes. On nonadopting farms, TE is decreased, as this change alters the position of the frontier value (such as any technological change would do). On adopting farms, in contrast, the increased harvest index (HI) would be cancelled out in the TE calculation.

The significance of different reference values becomes particularly apparent in a scenario with increasing yields that result from newly available technologies within a region. As frontier yields in the TE approach are technology-dependent, an innovation would increase the frontier yields. Concurrently, TE on farm units that do not adopt technological change would decrease, indicating a reduction in intensity despite the inputs and outputs of these areas remaining constant. This is a caveat when interpreting TE directly as an indicator of land-use intensity. In contrast, TE is a powerful indicator that can help detecting technology-dependent potentials for closing yield gaps. HANPP reacts differently to technology-driven yield increases, depending on whether such increases are achieved by increasing biomass production, $\mathrm{NPP}_{\text {act }}$, or decreasing the biomass that remains in the ecosystem, $\mathrm{NPP}_{\mathrm{t}}$. Although HANPP does not change in the first case, it increases in the second case (as indicated previously, it would be possible to render this visible in the HANPP framework, but it would require separate analysis of the individual HANPP components). The $\tau$-factor "translates" technology-driven yield increases into increases of their respective indicators.

\subsubsection{Spatial Patterns of Land-Use Intensity}

Comparing the spatially explicit results of the different approaches is intricate because the differences shown in the global maps (Fig. 5.4) depend not only on the differences in concept and scope but also on data uncertainties (e.g., due to differences in input data or conversion factors). This makes it difficult to separate this noise from the signal. In principle, data regarding agricultural yield are similar for all three approaches. However, for the inter-comparisons of the spatial patterns, not only the datasets per se but also the downscaling techniques play an important role. TE, as calculated by Neumann et al. (2010), for example, uses the census statisticderived dataset published by Monfreda et al. (2008), available at a 5-min geographic resolution (ca. $10 \times 10 \mathrm{~km}$ at the equator). In contrast, the $\tau$ calculation by Dietrich et al. (2012) uses the internal allocation rules of the vegetation model to downscale national harvest yields from FAO to a resolution of $0.5^{\circ}$. The HANPP map not only uses a different allocation technique based on the pattern of $\mathrm{NPP}_{0}$ but also refers to land-use yields rather than harvest yields, as discussed above.

Moreover, TE and the $\tau$-factor were originally developed for crop-specific analyses of land-use intensity (Dietrich et al. 2012; Neumann et al. 2010). Therefore, for the purpose of this study, the results had to be aggregated to display one intensity value per grid cell (see caption of Fig. 5.4). All of these aspects are important for interpreting the spatial patterns and differences. The map in Fig. 5.5 locates the areas of agreement and disagreement of the three approaches: TE, $\tau$ and HANPP. 


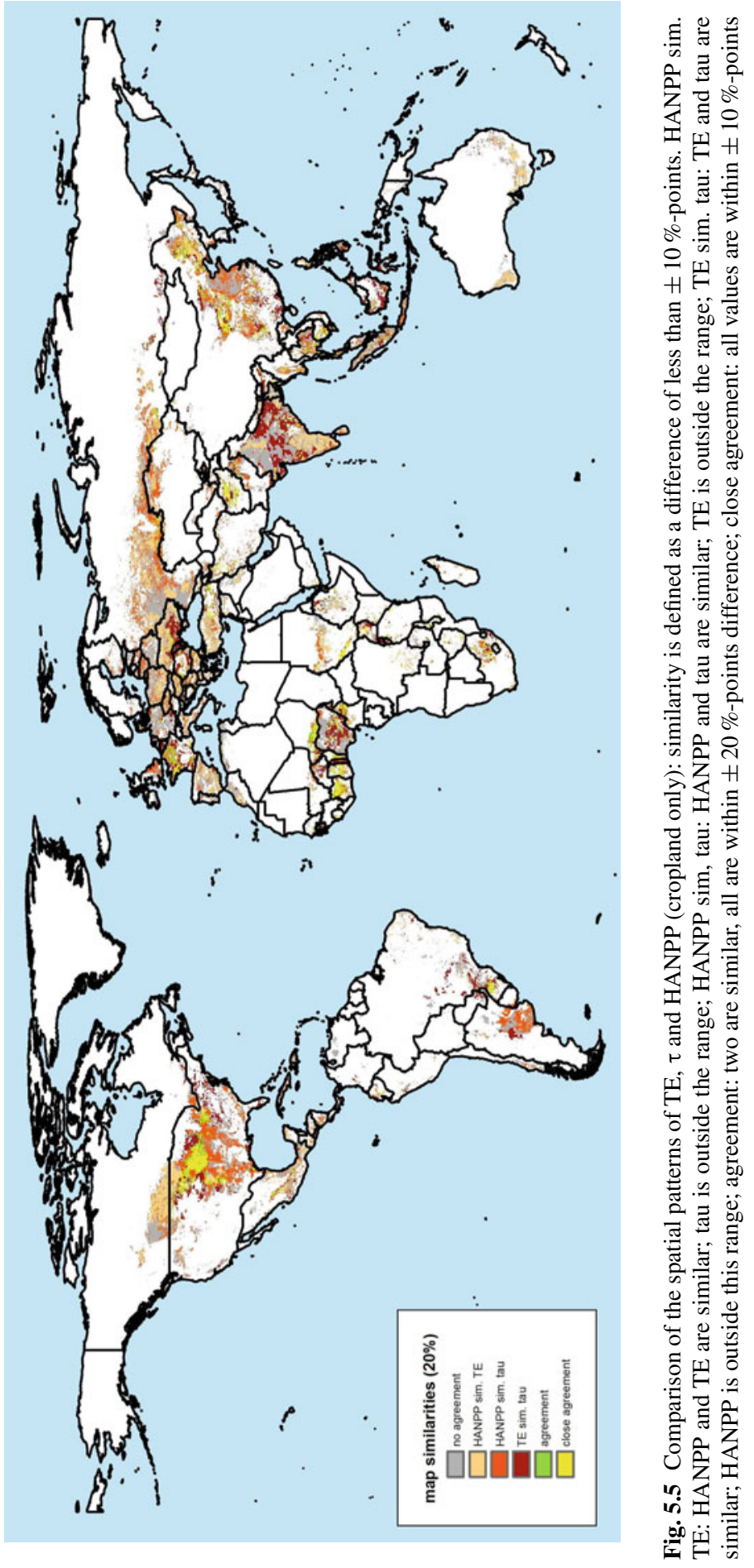


To discuss the differences in spatial patterns of the respective implementations of the three different approaches, we created an aggregated similarity map, which detects repeating patterns among the indicators (Fig. 5.5). Some adjustments were required for a consistent comparison. All of the values in the three maps were re-scaled to range between zero and one, to allow for consistent intercomparison. Additionally, negative HANPP values were not considered. The final map is restricted to the pixels contained in the TE map, which only covers the cultivation areas of maize, rice or wheat. All other land-use areas were excluded. Yellow regions in the map (close agreement) indicate that all three approaches yield similar results for land-use intensity. This is given if the difference is less than $10 \%$-points in each pixel. ${ }^{2}$ Green regions (agreement) are defined as regions in which two indicators show similar results (percentage-points closer than $\pm 10 \%$ ) and all three indicators lie within $20 \%$ points. It is apparent that green regions tend to be clustered around yellow regions, revealing a gradient from complete agreement to less or eventually no agreement.

Areas of Agreement A significant proportion (11\%) of the covered land area shows good (all three indicators within $\pm 10 \%$ ) or moderate agreement (two indicators within $\pm 10 \%$, one within $\pm 20 \%$ ). These are the regions with high land-use intensity in the Northern US, along the Mississippi river basin, and the Northern European croplands. These regions are characterised by high crop yields due to advanced agricultural production techniques (in particular, high levels of fertiliser application and irrigation). The TE in these regions approaches its maximum value of 1, indicating that actual yields approach frontier yields here. Additionally the $\tau$-factor ranges up to its maximum level of 2 in these regions, indicating that actual yields are twice as high as their reference yields. Likewise, HANPP shows its highest values here as well, ranging up to greater than $80 \%$ of the total $\mathrm{NPP}_{0}$.

Agreement with moderate intensity (with TE approximately 0.5 , $\tau$-factors approximately 1 and HANPP approximately $30-50 \%$ of $\mathrm{NPP}_{0}$ ) can be found in the cropland regions in North-eastern China, the Philippines, some Eastern European countries (Romania, Bulgaria) and southern Brazil. High agreement among the three indicators can be found in some regions of Sub-Saharan Africa (along the Gulf of Guinea coast and the Sahel zone), and some hotspots are also found in the easternmost parts of Europe (Ukraine), all areas with moderate-to-low intensity. In particular, the SubSaharan African countries situated in these regions often suffer from the combined effects of climatic constraints and the lack of agricultural means of production. However, reasons for this intricacy are manifold. In many cases, failed states, political constraints, poverty, and soil degradation pose restrictions to intensive agricultural production. In TE-terms, the distance from actual yields to the yield frontier in these parts of the world is still high, indicating a huge potential for future yield increases if improved management strategies are adopted. To harness these great potentials,

\footnotetext{
${ }^{2}$ Nota bene-this was calculated by subtraction and not as a ratio. We defined close agreement as when the difference of intensity values is less than $10 \%$-points (thus, shows a similar "class" of intensity). Such an approach leads to different results than calculating the ratio between two datasets and defining a similarity range (e.g., $\pm 10 \%$ deviation).
} 
however, will require sensitive strategies to avoid the many possible detrimental social and ecological impacts of land-use intensification (Foley et al. 2011; Friis and Reenberg 2010; Haberl et al. 2010; Lambin and Meyfroidt 2011; Young 1999).

Areas of Disagreement For much greater areas, however, the results of the three intensity calculations differ significantly. For $35 \%$ of the covered area, complete disagreement among the three indicators prevails, with hotspots concentrated in Canada, North-western India, Northern Europe, Western Russia, and along the North African Mediterranean coast. For the majority of the covered area $(53 \%)$, two indicators are similar to each other but differ significantly from the third. All three possible cases of this type are approximately equal in size: a HANPP similar to $\tau$ but dissimilar to TE is found in $20 \%$ of the area, a HANPP similar to TE but dissimilar to $\tau$ is found in $17 \%$, and a TE similar to $\tau$ but dissimilar to HANPP in $16 \%$.

These areas of disagreement are spread evenly throughout the entire global land surface. Several areas in South-eastern Europe, Canada, Southern India, Northern China and South Australia exhibit similar HANPP and TE patterns that are different from $\tau$. Vast parts of China, the US, Southern Brazil and Southern Russia reveal similarities between the HANPP and the $\tau$-factor, whereas TE disagrees. The $\tau$-factor and the TE largely agree but are not line with HANPP for areas in central India, Eastern Europe, Sub-Saharan Africa and South America. Reasons for this are manifold and are often an effect of specific different methodological features of the indicators.

The disagreement can be caused by conceptual differences but also by the differences in scope. Agreement is likely in areas where the sum of maize, wheat and rice dominates cropland (TE similar to $\tau$ ). Additionally, discrepancies between HANPP and the other two indicators are likely in areas that are not dominated by cropland but are heavily grazed, under forestry, or densely settled. The disagreement of $\tau$ and HANPP with TE can occur in areas where, at a large geographic scale, the potential for cultivation is not fully utilised, and the frontier yield is lower in the entire region, e.g., due to social or economic reasons. Major areas in which both TE and $\tau$ disagree with HANPP are at least partially due to multiple cropping, which is due to the differences in yield definition: HANPP refers to land-use yields (total annual production per area under cropland use, including fallows), whereas TE and $\tau$ refer to harvest yields (production per harvested area and harvest event; fallows are excluded, total annual production is divided by the area times harvest events, i.e., times three in the case of three harvests per year). Under the assumption of the equal inputs (e.g., irrigation), the $\tau$-factor approach on croplands situated in less favourable growth regions is likely to show higher $\tau$-values than in the more humid regions. One reason for this is that reference yields are lower in less favourable climatic regions. As these regions show a greater response to irrigation than do humid regions, actual yields can greatly exceed reference yields under appropriate management. In contrast, regions characterised by more favourable biophysical crop growth conditions (e.g., less water-stress, appropriate temperatures, and rich soils) are characterised by high reference yields. They thus already exhibit high actual yields under lower inputs into the land and hence also show less response to irrigation. 


\subsection{Conclusions}

Approximately three quarters of the terrestrial surface are used more or less intensively for, or at least affected by, settlements and infrastructure, cropping, grazing or forestry. The remaining quarter encompasses the remaining primary forests, natural grasslands and dry or cold deserts (Erb et al. 2007). At the same time, a growing and increasingly affluent world population that intends to satisfy its consumption needs and achieve a higher level of renewable energy supply will consume more biomass-even if the potentials for switching towards diets with reduced fraction of animal products in wealthy regions are realised and biomass is used more cautiously and efficiently (Erb et al. 2009a, 2012). Future increases in biomass supply for food, fibre and bioenergy will therefore primarily have to rely on changes in land-use intensity, as humanity struggles to limit the conversion of the last remaining pristine ecosystems (Foley et al. 2011). The search for sustainable options for intensification is therefore of utmost importance for feeding and fuelling the world.

Land-use intensity is a multi-faceted, complex concept. Increased land-use intensity can help reduce land demand and produce more food, fibre or bioenergy from constant or even shrinking land areas (Balmford et al. 2005; Burney et al. 2010; Rudel 2009). In contrast, negative environmental consequences of land-use intensity, such as falling energy return on investment (EROI) (Giampietro and Mayumi 2009; Hall et al. 1986, 2001, 2009; Pimentel 2008), soil degradation, nitrogen leaching, and the toxic effects of pesticides, have become widespread, and concern over these pressures is mounting (IAASTD 2009). Reliable and integrated socio-ecological indicators of land-use intensity are an important component of any effort to reap the benefits of land-use intensification while minimising its negative environmental consequences (Erb 2012).

Inspired by Boserup's seminal writings, this chapter has reviewed three different approaches to measuring land-use intensity: (1) TE, i.e., the distance between current crop yields and the highest possible yields given current technology; (2) the $\tau$-factor, the distance between current crop yields with and model-derived yields standardising technology; and (3) HANPP, the distance between the energy flow in ecosystems after harvest and the (hypothetically) undisturbed energy flow. Although each of these indicators has its specific strengths, none provides an all-encompassing solution to measuring land-use intensity. TE is best suited to identify "yield gaps", i.e., potential to improve crop yields by using the best available technologies. The $\tau$-factor is best suited to compare land-use intensity on cropland across time and space without having to use a time-dependent reference line such as "best currently available technology". Both measures are currently only defined for cropland and have difficulties in dealing with fallow land and multi-cropping, the aspect of land-use intensity that was the primary focus of Boserup's work. HANPP can help in both of these regards: it can measure land-use intensity across land-use classes, can address multi-cropping and fallow, and uses a natural science based, technology-independent reference line. However, compared with the other approaches, it does not capture the dominant effect of agricultural intensification on cropland, which occurs when 
technological improvements result in a parallel increase in primary production and harvests, see Krausmann et al. (2012).

We conclude that the search for integrated socio-ecological indicators of land-use intensity is an important topic of future land-change and sustainability science. Ester Boserup's seminal work will continue to provide an important source of inspiration for this highly topical area of research.

Acknowledgments The authors gratefully acknowledge funding from ERC Starting Grant 263522 LUISE and EU-FP7 265104 VOLANTE. Thanks go to Christian Lauk, Veronika Gaube, Thomas Kastner, and Katharina Waha for many insightful discussions and comments. This chapter contributes to the Global Land Project (http://www.globallandproject.org/).

Open Access This chapter is distributed under the terms of the Creative Commons Attribution Noncommercial License, which permits any noncommercial use, distribution, and reproduction in any medium, provided the original author(s) and source are credited.

\section{References}

Alexandratos, N. (2006). Prospects for food, nutrition, agriculture and major commodity groupsWorld agriculture: Towards 2030/2050-Interim report. Rome: FAO.

Allen, B. J. (2001). Boserup and brookfield and the association between population density and agricultural intensity in Papua New Guinea. Asia Pacific Viewpoint, 42, 236-254.

Balmford, A., Green, R. E., \& Scharlemann, J. P. W. (2005). Sparing land for nature: Exploring the potential impact of changes in agricultural yield on the area needed for crop production. Global Change Biology, 11, 1594-1605.

Blaikie, P. M., \& Brookfield, H. C. (1987). Land degradation and society. London: Methuen.

Bondeau, A., et al. (2007). Modelling the role of agriculture for the 20th century global terrestrial carbon balance. Global Change Biology, 13, 679-706.

Boserup, E. (1965). The conditions of agricultural growth: The economics of agrarian change under population pressure. London: Earthscan.

Boserup, E. (1981). Population and technological change: A study of long-term trends. Chicago: University of Chicago Press.

Brookfield, H. C. (2001). Intensification, and alternative approaches to agricultural change. Asia Pacific Viewpoint, 42, 181-192.

Brookfield, H. C., \& Hart, D. (1971). Melanesia: A geographical interpretation of an island world. London: Methuen.

Bruinsma, J. (2003). World agriculture: Towards 2015/2030. Rome: FAO.

Burney, J. A., Davis, S. J., \& Lobell, D. B. (2010). Greenhouse gas mitigation by agricultural intensification. Proceedings of the National Academy of Sciences of the United States of America, 107, 12052-12057.

Cannell, M. G. R. (1982). World forest biomass and primary production data. New York: Academic Press.

Chayanov, A. V. (1986). The theory of peasant economy. Madison: University of Wisconsin Press. Coelli, T. (2005). An introduction to efficiency and productivity analysis. New York: Springer.

Cohen, J. E. (1995). How many people can the earth support? New York: Norton.

Cramer, W., et al. (1999). Comparing global models of terrestrial net primary productivity (NPP): Overview and key results. Global Change Biology, 5(Suppl. 1), 1-15. 
Dietrich, J. P. (2011). Efficient treatment of cross-scale interactions in a land-use model. Dissertation, Humboldt-Universität zu Berlin, Faculty of Mathematics and Natural Sciences I, published 01.11.2011, urn:nbn:de:kobv:11-100196406.

Dietrich, J. P., Schmitz, C., Müller, C., Fader, M., Lotze-Campen, H., \& Popp, A. (2012). Measuring agricultural land-use intensity: A global analysis using a model-assisted approach. Ecological Modelling, 232, 109-118.

Erb, K. (2012). How a socio-ecological metabolism approach can help to advance our understanding of changes in land-use intensity. Ecological Economics, 76, 8-14.

Erb, K., Gaube, V., Krausmann, F., Plutzar, C., Bondeau, A., \& Haberl, H. (2007). A comprehensive global 5 min resolution land-use data set for the year 2000 consistent with national census data. Journal of Land Use Science, 2, 191-224.

Erb, K., Gingrich, S., Krausmann, F., \& Haberl, H. (2008). Industrialization, fossil fuels, and the transformation of land use. Journal of Industrial Ecology, 12, 686-703.

Erb, K., et al. (2009a). Eating the planet: Feeding and fuelling the world sustainably, fairly and humanely - a scoping study. Vienna: Institute of Social Ecology.

Erb, K., et al. (2009b). Analyzing the global human appropriation of net primary production: Processes, trajectories, implications. An introduction. Ecological Economics, 69, 250-259.

Erb, K., et al. (2012). The interrelations of future global bioenergy potentials, food demand and agricultural technology. Cambridge: Cambridge University Press.

FAOSTAT (Food and Agriculture Organization of the United Nations, Statistical Databases). (2011). FAOSTAT, FAO Statistical Databases: Agriculture, Fisheries, Forestry, Nutrition.

Fischer-Kowalski, M., \& Haberl, H. (Eds.). (2007). Socioecological transitions and global change: Trajectories of social metabolism and land use. Cheltenham: Edward Elgar Publishing.

Foley, J. A., et al. (2011). Solutions for a cultivated planet. Nature, 478, 337-342.

Friis, C., \& Reenberg, A. (2010). Land grab in Africa: Emerging land system drivers in a teleconnected world. GLP Report 1. Copenhagen: GLP International Project Office.

Gerten, D., Schaphoff, S., Haberlandt, U., Lucht, W., \& Sitch, S. (2004). Terrestrial vegetation and water balance-hydrological evaluation of a dynamic global vegetation model. Journal of Hydrology, 286, 249-270.

Giampietro, M., \& Mayumi, K. (2009). The biofuel delusion: The fallacy of large-scale agro-biofuel production. London: Earthscan.

GLP (Global Land Project). (2005). Science plan and implementation strategy. IGBP Report No. 53/ IHDP Report No. 19. Stockholm: IGBP.

Green, R. E., Cornell, S. J., Scharlemann, J. P. W., \& Balmford, A. (2005). Farming and the fate of wild nature. Science, 307, 550-555.

Grigg, D. (1979). Ester Boserup's theory of agrarian change: A critical review. Progress In Human Geography, 3, 64-84.

Haberl, H., Erb, K., Krausmann, F., Loibl, W., Schulz, N., \& Weisz, H. (2001). Changes in ecosystem processes induced by land use: Human appropriation of aboveground NPP and its influence on standing crop in Austria. Global Biogeochemical Cycles, 15, 929-942.

Haberl, H., Fischer-Kowalski, M., Krausmann, F., Weisz, H., \& Winiwarter, V. (2004). Progress towards sustainability? What the conceptual framework of material and energy flow accounting (MEFA) can offer. Land Use Policy, 21, 199-213.

Haberl, H., et al. (2007). Quantifying and mapping the human appropriation of net primary production in earth's terrestrial ecosystems. Proceedings of the National Academy of Sciences of the United States of America, 104, 12942-12947.

Haberl, H., Beringer, T., Bhattacharya, S. C., Erb, K., \& Hoogwijk, M. (2010). The global technical potential of bio-energy in 2050 considering sustainability constraints. Current Opinion in Environmental Sustainability, 2, 394-403.

Hall, C. A. S., Cleveland, C. J., \& Kaufmann, R. (1986). Energy and resource quality: The ecology of the economic process. New York: Wiley.

Hall, C. A. S., Lindenberger, D., Kümmel, R., Kroeger, T., \& Eichhorn, W. (2001). The need to reintegrate the natural sciences with economics. BioScience, 51, 663-673. 
Hall, C. A. S., Balogh, S., \& Murphy, D. J. R. (2009). What is the minimum EROI that a sustainable society must have? Energies, 2, 25-47.

Herzog, F., et al. (2006). Assessing the intensity of temperate European agriculture at the landscape scale. European Journal of Agronomy, 24, 165-181.

Hunt, R. C. (2000). Labor productivity and agricultural development: Boserup revisited. Human Ecology, 28, 251-277.

IAASTD (International Assessment of Agricultural Knowledge, Science and Technology for Development). (2009). Agriculture at a crossroads. Global Report. Washington, DC: Island Press.

Keys, E., \& McConnell, W. J. (2005). Global change and the intensification of agriculture in the tropics. Global Environmental Change, Part A, 15, 320-337.

Krausmann, F. (2001). Land use and industrial modernization: An empirical analysis of human influence on the functioning of ecosystems in Austria 1830-1995. Land Use Policy, 18, 17-26.

Krausmann, F., Erb, K., Gingrich, S., Lauk, C., \& Haberl, H. (2008). Global patterns of socioeconomic biomass flows in the year 2000: A comprehensive assessment of supply, consumption and constraints. Ecological Economics, 65, 471-487.

Krausmann, F., et al. (2012). Long-term trajectories of the human appropriation of net primary production: Lessons from six national case studies. Ecological Economics, 77, 129-138.

Lambin, E. F., \& Meyfroidt, P. (2011). Global land use change, economic globalization, and the looming land scarcity. Proceedings of the National Academy of Sciences of the United States of America, 108, 3465-3472.

Lambin, E. F., Rounsevell, M. D. A., \& Geist, H. J. (2000). Are agricultural land-use models able to predict changes in land-use intensity? Agriculture, Ecosystems \& Environment, 82, 321-331.

Lambin, E. F., et al. (2001). The causes of land-use and land-cover change: Moving beyond the myths. Global Environmental Change, 11, 261-269.

Licker, R., et al. (2010). Mind the gap: How do climate and agricultural management explain the "yield gap" of croplands around the world? Global Ecology and Biogeography, 19, 769-782.

Lieth, H. (1973). Primary production: Terrestrial ecosystems. Human Ecology, 1, 303-332.

Lieth, H., \& Whittaker, R. H. (1975). Primary productivity of the biosphere. Berlin: Springer.

Matson, P. A., Parton, W. J., Power, A. G., \& Swift, M. J. (1997). Agricultural intensification and ecosystem properties. Science, 277, 504-509.

McCloskey, J. M., \& Spalding, H. (1989). A reconnaissance-level inventory of the amount of wilderness remaining in the world. Ambio, 18, 221-227.

McNeill, J. R. (2001). Something new under the sun: An environmental history of the twentiethcentury world. New York: Norton.

MEA (Millennium Ecosystem Assessment). (2005). Ecosystems and human well-being: Current state and trends (Vol. 1). Washington, DC: Island Press.

Monfreda, C., Ramankutty, N., \& Foley, J. A. (2008). Farming the planet: 2. Geographic distribution of crop areas, yields, physiological types, and net primary production in the year 2000. Global Biogeochemical Cycles, 22(GB1022), 1-19.

Netting, R. M. C. (1993). Smallholders, householders: Farm families and the ecology of intensive, sustainable agriculture. Stanford: Stanford University Press.

Neumann, K., Verburg, P. H., Stehfest, E., \& Müller, C. (2010). The yield gap of global grain production: A spatial analysis. Agricultural Systems, 103, 316-326.

Pimentel, D. (2008). Biofuels, solar and wind as renewable energy systems: Benefits and risks. Dordrecht: Springer.

Pingali, P. L., Bigot, Y., \& Binswanger, H. P. (1987). Agricultural mechanization and the evolution of farming systems in sub-Saharan Africa. Baltimore: Johns Hopkins University Press.

Popp, A., et al. (2011). Bioenergy costs and potentials with special attention to implications for the land system. AGU Fall Meeting Abstracts-1, 06.

Portmann, F. T., Siebert, S., \& Döll, P. (2010). MIRCA2000-Global monthly irrigated and rainfed crop areas around the year 2000: A new high-resolution data set for agricultural and hydrological modeling. Global Biogeochemical Cycles, 24, GB1011. 
Robinson, W., \& Schutjer, W. (1984). Agricultural development and demographic change: A generalization of the Boserup model. Economic Development and Cultural Change, 32, 355-366.

Roy, J., Saugier, B., \& Mooney, H. A. (Eds.). (2001). Terrestrial global productivity. San Diego: Academic Press.

Rudel, T. K. (2009). Agricultural intensification and changes in cultivated areas, 1970-2005. Proceedings of the National Academy of Sciences of the United States of America, 106, 20675-20680.

Ruthenberg, H. (1980). Farming systems in the tropics. Oxford: Clarendon Press.

Sanderson, E. W., Jaiteh, M., Levy, M. A., Redford, K. H., Wannebo, A. V., \& Woolmer, G. (2002). The human footprint and the last of the wild. BioScience, 52, 891-904.

Schmitz, C., et al. (2012). Trading more food: Implications for land use, greenhouse gas emissions, and the food system. Global Environmental Change, 22, 189-209.

Shriar, A. (2000). Agricultural intensity and its measurement in frontier regions. Agroforestry Systems, 49, 301-318.

Siebert, S., Portmann, F. T., \& Döll, P. (2010). Global patterns of cropland use intensity. Remote Sensing, 2, 1625-1643.

Sieferle, R. P., Krausmann, F., Schandl, H., \& Winiwarter, V. (2006). Das Ende der Fläche: Zum gesellschaftlichen Stoffwechsel der Industrialisierung. Cologne. Germany: Böhlau.

Sitch, S., et al. (2003). Evaluation of ecosystem dynamics, plant geography and terrestrial carbon cycling in the LPJ dynamic global vegetation model. Global Change Biology, 9, 161-185.

Steffen, W., Crutzen, P. J., \& McNeill, J. R. (2007). The anthropocene: Are humans now overwhelming the great forces of nature. Ambio, 36, 614-621.

Tian, W., \& Wan, G. H. (2000). Technical efficiency and its determinants in China's grain production. Journal of Productivity Analysis, 13, 159-174.

Tiffen, M., Mortimore, M., \& Gichuki, F. (1994). More people, less erosion: Environmental recovery in Kenya. Chichester: Wiley.

Turner, B. L. II, \& Doolittle, W. (1978). The concept and measure of agricultural intensity. The Professional Geographer, 30, 297-301.

Turner, B. L. II, \& Fischer-Kowalski, M. (2010). Ester Boserup: An interdisciplinary visionary relevant for sustainability. Proceedings of the National Academy of Sciences of the United States of America, 107, 21963-21965.

Turner, B. L. II, \& Shajaat Ali, A. M. (1996). Induced intensification: Agricultural change in Bangladesh with implications for Malthus and Boserup. Proceedings of the National Academy of Sciences of the United States of America, 93, 14984-14991.

Turner, B. L. II, Hanham, R. Q., \& Portararo, A. V. (1977). Population pressure and agricultural intensity. Annals of the Association of American Geographers, 67, 384-396.

Turner, B. L. II, Lambin, E. F., \& Reenberg, A. (2007). The emergence of land change science for global environmental change and sustainability. Proceedings of the National Academy of Sciences of the United States of America, 104, 20666-20671.

VanWey, L. K., Ostrom, E., \& Meretsky, V. (2005). Theories underlying the study of humanenvironment interactions. In E. F. Moran \& E. Ostrom (Eds.), Seeing the forest and the trees: Human-environment interactions in forest ecosystems (pp. 23-56). Cambridge: MIT Press.

Verburg, P. H., Chen, Y., \& Veldkamp, T. (2000). Spatial explorations of land use change and grain production in China. Agriculture, Ecosystems \& Environment, 82, 333-354.

Verburg, P. H., Neumann, K., \& Nol, L. (2011). Challenges in using land use and land cover data for global change studies. Global Change Biology, 17, 974-989.

Vitousek, P. M., Ehrlich, P. R., Ehrlich, A. H., \& Matson, P. A. (1986). Human appropriation of the products of photosynthesis. BioScience, 36, 368-373.

Young, A. (1999). Is there really spare land? A critique of estimates of available cultivable land in developing countries. Environment, Development and Sustainability, 1, 3-18.

Zaks, D. P. M., Ramankutty, N., Barford, C. C., \& Foley, J. A. (2007). From Miami to Madison: investigating the relationship between climate and terrestrial net primary production. Global Biogeochemical Cycles, 21, GB3004. 